\title{
Impacts of Madden-Julian Oscillation on tropical cyclone activity over the western North Pacific under global warming
}

\author{
Lan Thi Dao, Li-Chiao Wang, and Jia-Yuh Yu*
}

Department of Atmospheric Sciences, National Central University, Taoyuan City, Taiwan

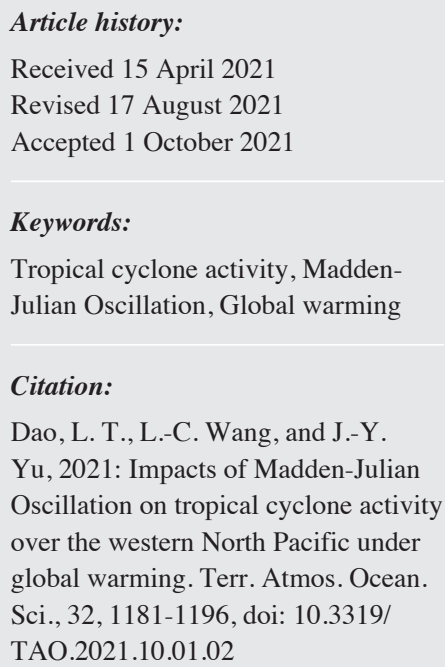

\begin{abstract}
The modulation of tropical cyclone (TC) activity by Madden Julian Oscillation (MJO) in the western North Pacific (WNP) is investigated based on simulation results from a pair of Hi-Resolution Atmospheric Model (HiRAM) experiments, one designed for the present-day simulation $\left(1980\right.$ - 2004) and the other for the late $21^{\text {st }}$ century projection (2075 - 2099) with the Representative Concentration Pathway (RCP) 8.5 warming scenario, at approximately $25 \mathrm{~km}$ spatial resolution. Major features of the observed TCs, such as the seasonal cycle, spatial distribution of TC genesis and the modulation of MJO on TC activity, are properly reproduced by HiRAM. Under global warming, HiRAM projects a marked reduction of TC genesis in all phases of MJO and a greater daily genesis rate (DGR) contrast between the enhanced (e.g., 4, 5 , and 6 ) and suppressed (e.g., 7, 8, 1, 2, and 3 ) phases during the late $21^{\text {st }}$ century period (2075 - 2099) against the present-day period (1980 - 2004). A modified "genesis potential index" (GPI) is proposed to elucidate the environmental factors attributing to TC activity change associated with MJO. A budget analysis of GPI clearly indicates that the suppression of TC genesis associated with MJO under global warming should result mostly from decreases in low-level relative vorticity and mid-level relative humidity. The present study highlights an example of HiRAM's application in simulating the impacts of $\mathrm{MJO}$ on TC activity and projecting the potential changes of MJO-TC relation under global warming over the WNP warm pool.
\end{abstract}

\section{INTRODUCTION}

The western North Pacific (WNP) is the most active basin for tropical cyclone (TC) formation, accounting for about $30 \%$ of the total number of TCs around the globe (Yumoto and Matsuura 2001; Chan 2005). On average, about 26 TCs form in the WNP each year but the genesis number is subject to marked variations on various (e.g., intraseasonal, interannual, and interdecadal) timescales. At intraseasonal timescales, the Madden Julian Oscillation (MJO; Madden and Julian 1971), characterized by an eastward-propagating, planetary-scale structure of zonal winds and convection with a period of around 30 - 60 days, is considered as the dominant climate variability affecting TC activity (including genesis number and track) in the WNP. Observational studies showed a significant increase (decrease) in TC genesis frequency in the WNP, including the
South China Sea (SCS), during the enhanced (suppressed) convection phase of MJO (Kim et al. 2008; Huang et al. 2011; Li and Zhou 2013; Yoshida et al. 2014; Zhao et al. 2015; Dao and Yu 2021a).

In addition to observational studies, the influences of MJO on TC activity were also examined using high resolution climate models. For instance, Jiang et al. (2012) showed that the modulations of MJO on TC genesis in the eastern Pacific are well simulated by the Geophysical Fluid Dynamics Laboratory (GFDL) High-Resolution Atmospheric Model (HiRAM), with a spatial resolution of approximately $50 \mathrm{~km}$. Kim et al. (2014) later demonstrated that although GEOS-5 simulates MJOs with a slightly faster propagation, the model to some extent may reproduce the observed modulations of TC activity by MJO in the WNP. Recently, Zhao and Li (2019) evaluated the importance of MJO dynamic and thermodynamic influence on TC activity in the WNP

\footnotetext{
* Corresponding author

E-mail:jiayuh@atm.ncu.edu.tw
} 
using the Advanced Research Version of the Weather Research and Forecasting model (WRW-ARW). They found that change in relative humidity is the most important factor for controlling TC genesis in the WNP. Zhao et al. (2019) also argued that both the Beijing Climate Center Climate System Model (BCC_CSM1.2) and Met Office global coupled model (GloSea5) can reproduce a positive (negative) genesis potential index (GPI) anomaly in the South China Sea (SCS) and WNP when the enhanced (suppressed) convection phase of MJO is located over these regions.

Because MJO plays an important role in modulating extreme weather events, many studies were conducted to investigate how MJO might change under global warming. Subramanian et al. (2014) noted that, under the warmest twenty-first century projection scenario-the Representative Concentration Pathway 8.5 (RCP 8.5), the intensity of MJO will be significantly enhanced, characterized by stronger rainfalls in the central and eastern tropical Pacific. Arnold et al. (2015) also indicated an increase in intraseasonal variance of the outgoing longwave radiation (OLR) and precipitation under global warming. Similarly, Bui and Maloney (2018) confirmed an increase (decrease) in precipitation (wind) variance associated with MJO under global warming. Moreover, Cui and Li (2019) found that the MJO tends to have a shorter period and a faster eastward propagation speed under global warming. In summary, a warmer climate would produce a more intense $\mathrm{MJO}$ variability which might impose a greater impact on severe weather events in the tropics, such as the TC activity (including genesis number and moving track).

While previous studies have investigated the potential changes of MJO under global warming, the changes in MJO-TC interaction have not been fully examined because of the relatively coarse spatial resolutions used in most of the state-of-the-art climate models. Dao and Yu (2021a) recently noted that, at $25 \mathrm{~km}$ horizontal resolution, HiRAM is capable of reproducing major features of the observed TC activity change associated with MJO variability over the WNP and SCS. In this study, we extend the work of Dao and $\mathrm{Yu}$ (2021a) further to investigate how the impacts of MJO on TC activity might change under global warming using a pair of HiRAM experiments: one for the presentday simulation $(1980-2004)$ and the other for the late $21^{\text {st }}$ century projection (2075 - 2099), with the RCP 8.5 emission scenario. The remainder of this paper is organized as follows. Section 2 introduces the data sources, experiment designs, algorithm for detecting TC-like vortices, method for dividing MJO phases, and the modified GPI for investigating environmental factors attributing to TC genesis change. Section 3 discusses the potential changes of TC activity associated with MJO under global warming and the mechanisms responsible for such changes based on the GPI budget analysis. Major findings are summarized and discussed in section 4 .

\section{DATA, MODEL AND METHODS}

\subsection{Data Sources}

The TC best-track data obtained from the Joint Typhoon Warning Center (JTWC) were used to verify the model's performance in simulating TC activity over the WNP. The best-track dataset provides 6-hourly information on TC location and intensity (measured as the maximum sustained wind speed over 1-minute interval) over the Northwest Pacific Ocean, South Pacific Ocean and Indian Ocean, covering the period from 1949 to the present. We also used the daily ERA-Interim data to calculate the GPI. The data were generated by the ERA-Interim reanalysis project at ECMWF (European Center for Medium-Range Weather Forecast) to improve some aspects of the earlier ERA-40 data (Dee et al. 2011). The ERA-Interim product provides a global coverage of meteorological variables at 37 pressure levels, with a spatial resolution of $0.5^{\circ}$ latitude $\times 0.5^{\circ}$ longitude, covering the period from 1979 to the present. The data period used in this study is from 1980 to 2004, focusing on the peak TC genesis season (June to November).

\subsection{Experiment Designs}

The HiRAM (Hi-Resolution Atmospheric Model), an atmospheric general circulation model developed at Geophysical Fluid Dynamics Laboratory (GFDL) of Princeton University, was adopted to simulate and project the impacts of MJO on TC activity in the WNP. The model is a modified version of the GFDL Atmospheric Model version 2.1 (AM2.1). HiRAM utilizes a special hydrostatic finite-volume cubed-sphere dynamic core (Lin 2004). Designed for global cloud-resolving capability, HiRAM uses a nonintrusive shallow convective scheme (Bretherton et al. 2004) and replaces the deep convective scheme by a six-category bulk cloud microphysics scheme for the resolved component of cumulus convection processes (Zhao et al. 2009).

In this study, two time-sliced experiments with a spatial resolution of $0.23^{\circ} \times 0.23^{\circ}$ were carried out. Specifically, HiRAM was forced by two sets of boundary conditions. The $1^{\text {st }}$ set adopted the monthly sea surface temperature (SST) and sea ice concentration (SIC) fields over the historical period of 1980 - 2004 from the Hadley Center HadISST dataset (Rayner et al. 2003). The $2^{\text {nd }}$ set utilized the monthly SST and SIC fields by superposing the future changes (anomalies) averaged over the period of 2075 - 2099 from the ensemble means of 28 Coupled Model Intercomparison Project, phase 5 (CMIP5) models with the RCP 8.5 scenario plus the linear trends and interannual variability (Hsu et al. 2021). For brevity, we refer the experiment forced by the $1^{\text {st }}$ set of boundary conditions as the present-day simulation and the experiment forced by the $2^{\text {nd }}$ set of boundary conditions as the late $21^{\text {st }}$ century projection. Moreover, due to the limitation of computer resource, it is very common to 
use one single high-resolution general circulation model to investigate the potential changes of TC activity under global warming (e.g., Murakami et al. 2011; Tsou et al. 2016; Dao and Yu 2021a, b; Hsu et al. 2021) because we need very high-resolution outputs in both space and time to detect the TC-like vortices. The HiRAM experiments use 32 vertical levels with a constant-pressure top at $10 \mathrm{hPa}$. All simulation outputs were stored at six-hourly intervals to be consistent with the JTWC best-track observation.

\subsection{Methods}

The model TCs are detected and tracked every six hours following the algorithm described in Dao and $\mathrm{Yu}$ (2021a). In short, the detection algorithm uses six thresholds from model outputs, including relative vorticity at $850 \mathrm{hPa}$, minimum sea level pressure, sea level pressure anomaly, temperature anomaly, geopotential height anomaly, and the outer core wind strength to identify potential TC-like vortices. Once detected, it must last at least 3 days to be considered as a TC event.

The multivariate Empirical Orthogonal Function (MEOF) method proposed by Wheeler and Hendon (2004) is utilized to extract the MJO signal. In practice, the MJO index is calculated based on a pair of eigenvectors (MEOF1 and MEOF2) derived from 850 and $200 \mathrm{hPa}$ zonal winds and OLR data over the global tropics $\left(15^{\circ} \mathrm{S}-15^{\circ} \mathrm{N}, 0-360^{\circ}\right)$. Two leading principal components (PC1 and PC2) are used to divide the MJO lifecycle into eight different phases. Because this study focuses on how MJO might modulate TC activity over the WNP, only results over the domain (0 $\left.30^{\circ} \mathrm{N}, 100-160^{\circ} \mathrm{E}\right)$ are plotted. To highlight the effect of MJO on TC activity, only those MJO events with the MJO index greater than or equal to one are chosen for composite.

Following previous studies (Kim et al. 2008; $\mathrm{Li}$ and Zhou 2013; Dao and Yu 2021a), the daily genesis rate (DGR), calculated as the number of TCs divided by the number of days for a specific MJO phase, is also used to compare the frequency of TC activity in different MJO phases.

\subsection{Genesis Potential Index (GPI)}

While the "genesis potential index" (GPI) proposed by Emanuel and Nolan (2004) (hereafter, ENGPI) has been widely used to investigate the environmental factors controlling TC activity change (Camargo et al. 2009; Murakami et al. 2011; Tsou et al. 2016; Zhao et al. 2019), some recent studies, however, showed that ENGPI tends to generate a rather poor performance in reproducing the observed longterm TC variability in the WNP (Yu et al. 2018; Hsiao et al. 2020). Wang and Moon (2017) argued that the effect of relative vorticity would be overshadowed by the Coriolis parameter in the off-equatorial TC genesis region when using absolute vorticity as an environmental factor in GPI.
Therefore, they used low-level relative vorticity weighted by the Coriolis parameter in their GPI designed for measuring MJO modulation on TCs. Following their concept, here we replace absolute vorticity in ENGPI by relative vorticity weighted by the Coriolis parameter as in Dao and $\mathrm{Yu}$ (2021b) to yield the following modified GPI:

$\mathrm{GPI}=\left|10^{10} \mathrm{fS}_{850}\right|^{3 / 2}\left(\frac{\mathrm{RH}}{50}\right)^{3}\left(\frac{\mathrm{V}_{\text {pot }}}{70}\right)^{3}\left(1+0.1 \mathrm{~V}_{\text {shear }}\right)^{-2}$

where $S_{850}$ is the relative vorticity at $850 \mathrm{hPa}\left(\mathrm{s}^{-1}\right), \mathrm{f}$ is the Coriolis parameter $\left(\mathrm{s}^{-1}\right), \mathrm{RH}$ is the relative humidity at 700 $\mathrm{hPa}(\%), \mathrm{V}_{\text {shear }}$ is the vertical wind shear magnitude between 850 and $200 \mathrm{hPa}\left(\mathrm{m} \mathrm{s}^{-1}\right)$, and $\mathrm{V}_{\text {pot }}$ is the maximum potential intensity of tropical cyclone $\left(\mathrm{m} \mathrm{s}^{-1}\right)$. The parameter $\mathrm{V}_{\text {pot }}$ defined by Bister and Emanuel (2002) is calculated as follows:

$\mathrm{V}_{\mathrm{pot}}^{2}=\frac{\mathrm{C}_{\mathrm{k}}}{\mathrm{C}_{\mathrm{D}}} \frac{\mathrm{T}_{\mathrm{s}}}{\mathrm{T}_{0}}\left(\mathrm{CAPE}^{*}-\mathrm{CAPE}^{\mathrm{b}}\right)$

where $C_{k}$ and $C_{D}$ denote the exchange coefficients for enthalpy and momentum, respectively, $\mathrm{T}_{\mathrm{s}}$ is $\mathrm{SST}(\mathrm{K})$ and $\mathrm{T}_{0}$ is the mean outflow temperature $(\mathrm{K})$. The quantity CAPE* is the saturation convective available potential energy (CAPE) at the radius of maximum wind, and $\mathrm{CAPE}^{\mathrm{b}}$ is $\mathrm{CAPE}$ value of the boundary layer air.

Following previous studies (Yu et al. 2018; Li and $\mathrm{Yu}$ 2020; Dao and Yu 2021b), a binary-logarithm is taken on Eq. (1) to yield

$\mathrm{cGPI}=\mathrm{cRV}+\mathrm{cRH}+\mathrm{cPI}+\mathrm{cVWS}$

where cGPI $=\log _{2}$ GPI, cRV $=\log _{2}\left|10^{10} \mathrm{fS}_{850}\right|^{3 / 2}$, cRH $=\log _{2}\left(\frac{\mathrm{RH}}{50}\right)^{3}, \mathrm{cPI}=\log _{2}\left(\frac{\mathrm{V}_{\text {pot }}}{70}\right)^{3}$, and cVWS $=\log _{2}(1+$ $\left.0.1 \mathrm{~V}_{\text {shear }}\right)^{-2}$. Using such a simple transformation, the change of cGPI now becomes a linear addition of the four environmental factors on the right-hand side of Eq. (3).

\section{MODULATIONS OF TC ACTIVITY BY MJO}

\subsection{TC Activity and MJO}

Before investigating the modulation of TCs by MJO under global warming, the changes of TC activity under global warming in HiRAM simulations are examined first. Figure 1 compares the annual cycle of TC genesis frequency in the WNP $\left(0-30^{\circ} \mathrm{N}, 100-160^{\circ} \mathrm{E}\right)$ during the presentday (1980 - 2004) and late $21^{\text {st }}$ century (2075 - 2099) periods. On average, about 25 TCs form per year during the present-day period. As shown, JJASON (June to November) is the most active season for TC formation, accounting for over $80 \%$ of the total TC number. While HiRAM seems to slightly overestimate the annual genesis number 
compared to observation ( 25 versus 30 ), the annual cycle pattern is well reproduced by HiRAM, with a correlation coefficient of 0.93 between simulation and observation. It is of particular importance to note that TCs are largely suppressed under global warming, with only 15 TCs forming per year during the future period compared to about $30 \mathrm{TCs}$ per year during the present-day period. This is corresponding to a $50 \%$ reduction in annual TC genesis number. The most significant drop of TCs occurs in the boreal summer and fall (JJASON). By using the same HiRAM model, Tsou et al. (2016) found both TC genesis numbers and passage frequency over the WNP are projected to significantly decrease ( 49\%) during the 2075 - 2099 period. They further pointed out that the decrease in TC genesis number should result from the reduction in mid-level relative humidity and large-scale ascending motions. The reduced low-level vorticity associated with monsoon trough weakening also plays a notable role to suppress TC genesis, especially over the Philippine Sea and South China Sea [see Fig. 15 of Tsou et al. (2016)].

Figure 2 compares the distribution of TC genesis locations during JJASON between JTWC observations and HiRAM simulations during the present-day and late $21^{\text {st }}$ century periods. On average, about 20.4 TCs form per year in the WNP. Although HiRAM slightly overestimates the annual TC genesis number compared to observation (22.2 versus 20.4), the spatial distribution of TC genesis locations is generally reproduced by HiRAM. Specifically, the correlation coefficient between observation and simulation is about 0.62 as shown by comparing the spatial distribution of TC genesis frequency between JTWC and HiRAM during the present-day period (see Figs. $2 b$ and d for comparison). According to the HiRAM projection (Figs. 2e and f), the TC annual genesis number would significantly decrease during the late $21^{\text {st }}$ period under the RCP 8.5 warming scenario compared to the present-day period (22.2 versus 9.8$)$ and the greatest reduction occurs over the domain $\left(10-20^{\circ} \mathrm{N}\right.$, $130-160^{\circ} \mathrm{E}$ ), in agreement with previous studies (e.g., Zhao et al. 2009; Murakami et al. 2012, 2014; Ying et al. 2012).

Because JJASON is the most active period for TC genesis in the WNP, in the following content, we only focus on this half-year period to examine how MJO might modulate TC activity in the WNP and how this modulation could change under global warming. Dao and Yu (2021a) investigated impacts of MJO on TC activity over the WNP comparing between observations and HiRAM simulations. Their study showed that HiRAM can properly reproduce major features of TC activity changes associated with MJO variability in observations. This study is an extension of our previous work to further examine how the TC-MJO relationship might change under global warming by comparing model simulation outputs between the present-day and late $21^{\text {st }}$ century periods.

Figures 3 and 4 show the composite anomalies of OLR and $850-\mathrm{hPa}$ winds in eight different $\mathrm{MJO}$ phases derived from the present-day and late $21^{\text {st }}$ century periods, respectively. During the present-day period, enhanced convection (negative OLR anomalies), along with a cyclonic circulation anomaly, appears over the SCS in phase 4. This enhanced convection then strengthens and propagates eastward during phases 5 and 6 . The greatest enhancement of convection occurs in phase 5 accompanied by a large-scale cyclonic circulation anomaly over the WNP. The suppressed convection (i.e., positive OLR anomalies) and easterly winds start to appear in phase 7 , and then they move eastward in phases 8,1 and 2. The largest suppression of convection occurs in phase 8 accompanied by an anticyclonic circulation over the entire SCS. Under global warming, the basic structure of MJO variability does not change too much except for weaker amplitudes of negative OLR anomalies (i.e., convection), especially from phases 4 to 6 (see Figs. 3 and 4 for comparison), which is consistent with the suppressed TC formation during this period. The enhanced convection phases extend longer from phase 4 to 7 under global warming compared to phase 4 to 6 in the present-day simulation. As a result, major discrepancies between the present-day and future simulations exist in phases 6 and 7. In the future simulation, the negative OLR anomalies and westerlies cover the entire WNP domain in phase 6 , not just the eastern part as shown in the present-day simulation. Similarly, the enhanced convection signal still exists in phase 7 under global warming; while the suppressed convection and easterlies already dominate the entire SCS in the present-day simulation.

Figure 5 shows the initial genesis locations of TCs in eight different phases of MJO in the present-day simulation (1980 - 2004). More TCs form in phases 4 and 5 when enhanced convection dominates over the WNP. To provide a quantitative view, Table 1 summarizes the DGR of TCs in eight different MJO phases. As shown, greater values of DGR occur in phases 4, 5, and 6; while smaller values of DGR appear in phases 8, 1,2, and 3, in accordance with the enhanced convection and suppressed convection phases of MJO (see Fig. 3 for comparison). The initial genesis locations of TCs in eight different MJO phases in the late $21^{\text {st }}$ century projection $(2075$ - 2099) are illustrated in Fig. 6. Under global warming, TC genesis numbers in all phases significantly decrease. The total TC number in the late $21^{\text {st }}$ century projection is just a half of that in the present-day simulation (147 versus 302). As shown in Table 2, larger values of DGR occur during the active phases of convection (e.g., phases 4, 5, 6, and 7); while smaller values of DGR appear during the inactive phases (e.g., phases 8,1 , 2,3 ). The mean value of DGR from the late $21^{\text {st }}$ century projection is about a half of that from present simulation (5.5 versus 11.97). Moreover, the DGR contrast between enhanced and suppressed convection phases enhances under global warming. In the present-day simulation, the DGR value averaged over the enhanced convection phases is only 


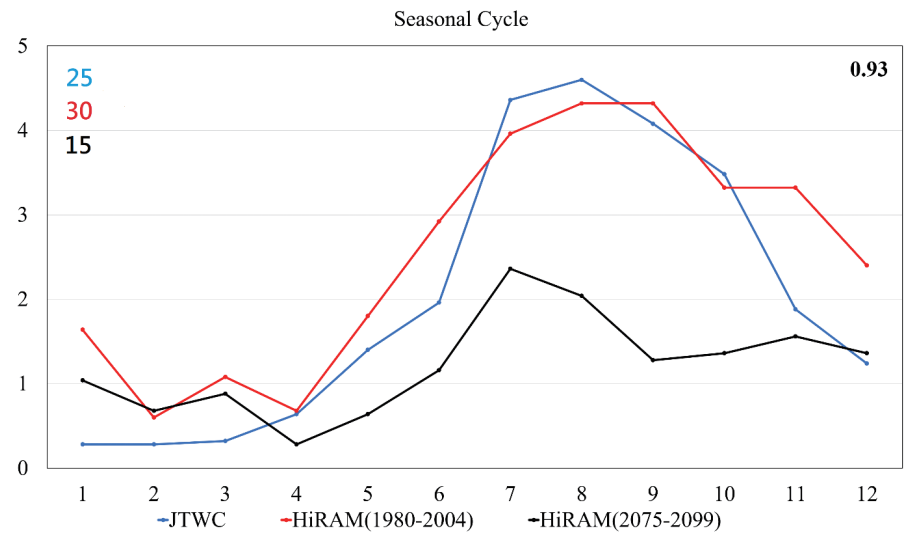

Fig. 1. Seasonal cycle of TC frequency (unit: TC number per month per year) for observation (blue line), HiRAM simulation (red line), and HiRAM projection (black line), with the respective annual mean TC genesis number displayed in the upper-left corner. The number in the top-right corner is the correlation coefficient between JTWC observation and HiRAM present-day simulation.

(a)

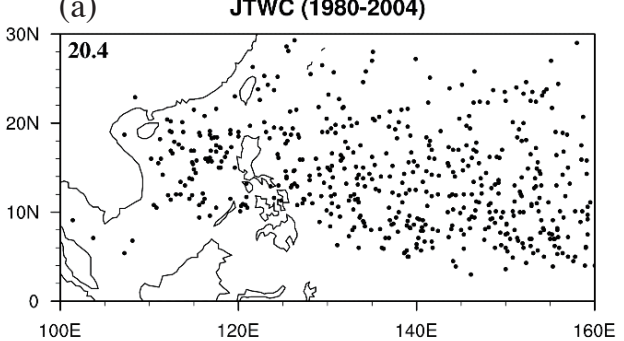

(c) HiRAM (1980-2004)

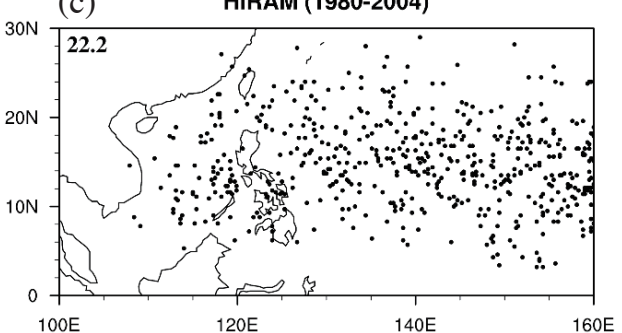

(e) HIRAM (2075-2099)

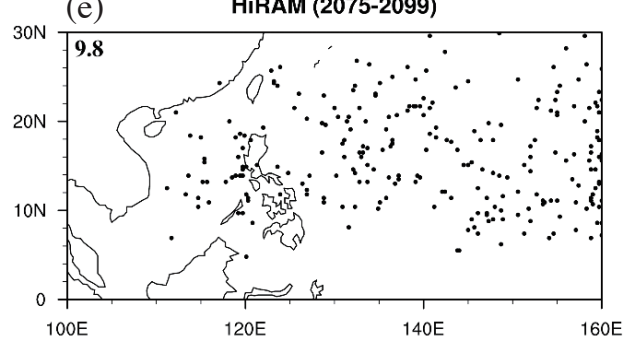

(b)

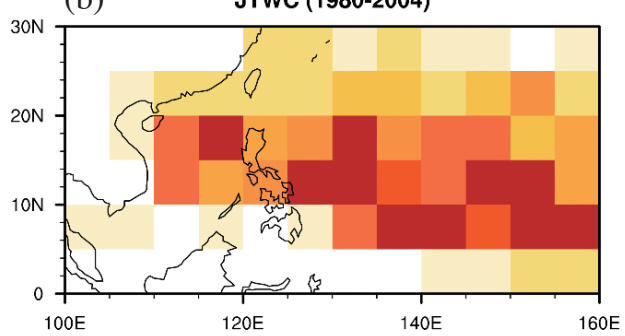

(d)

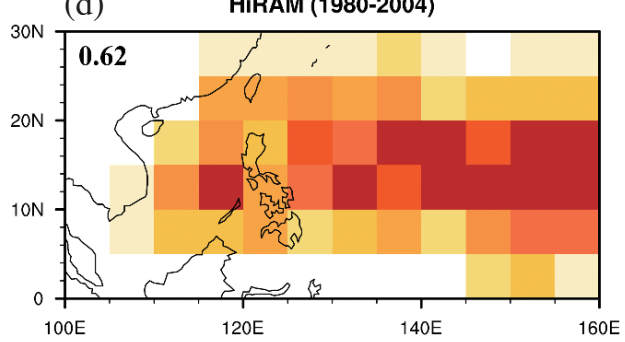

HiRAM (2075-2099)

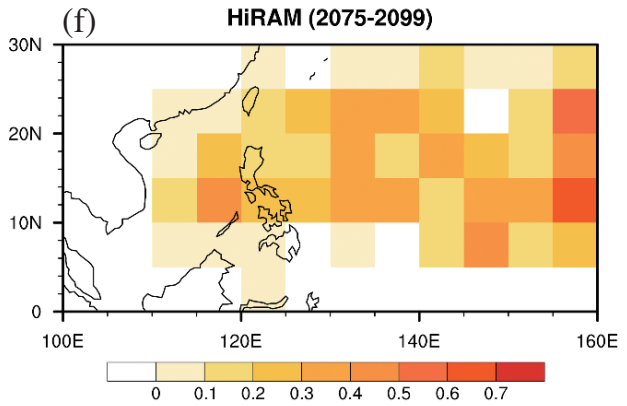

Fig. 2. The spatial patterns of TC genesis location (a) (c) (e) and genesis frequency (b) (d) (f) during the boreal summer (June to November) from the JTWC observation, HiRAM present-day simulation, and HiRAM late $21^{\text {st }}$ century projection. The numbers in the top-left corners of (a) (c) (e) are TC total numbers (unit: numbers per year). The number displayed in the top-left corner of (d) denotes the correlation coefficient between (b) and (d). 

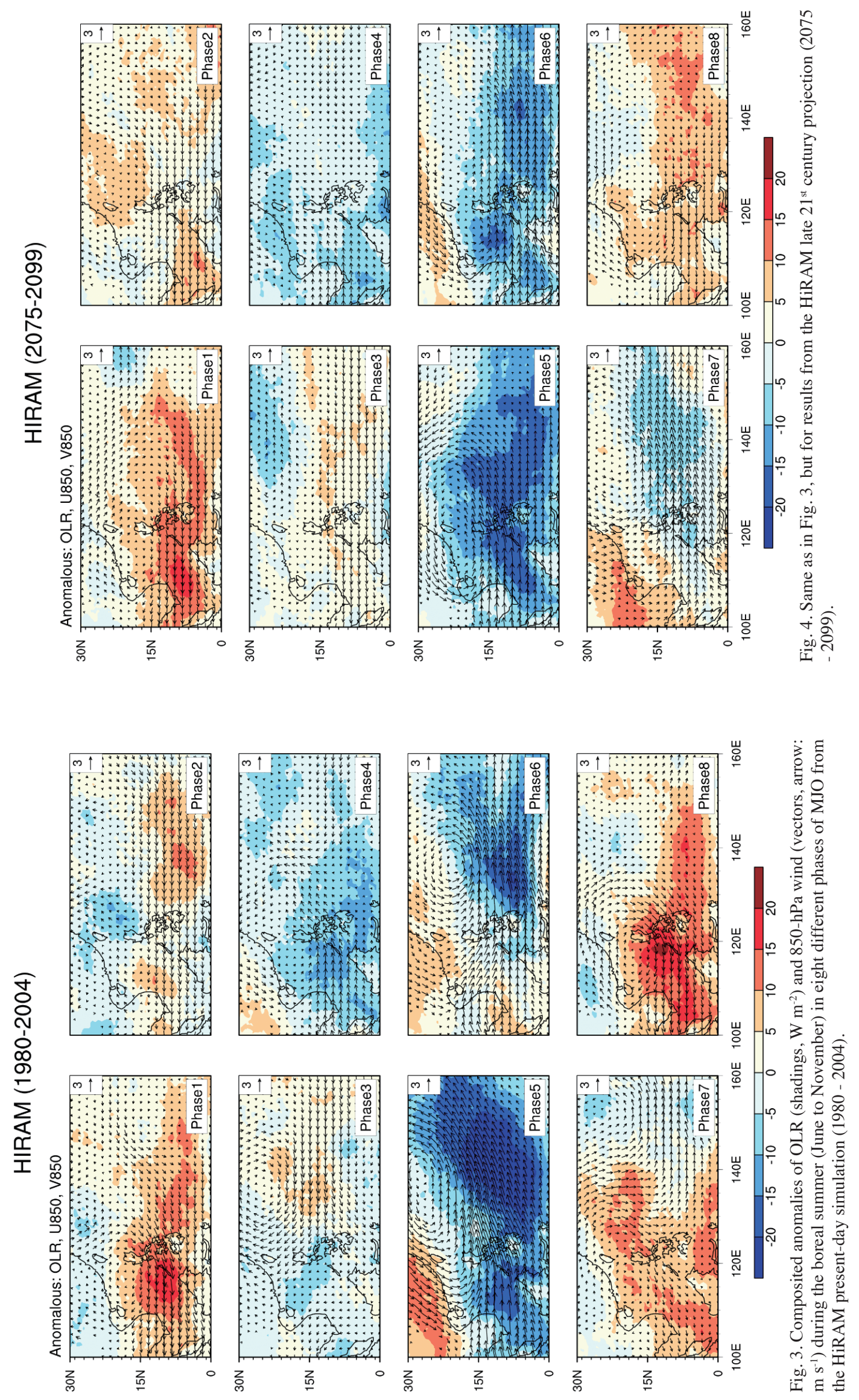

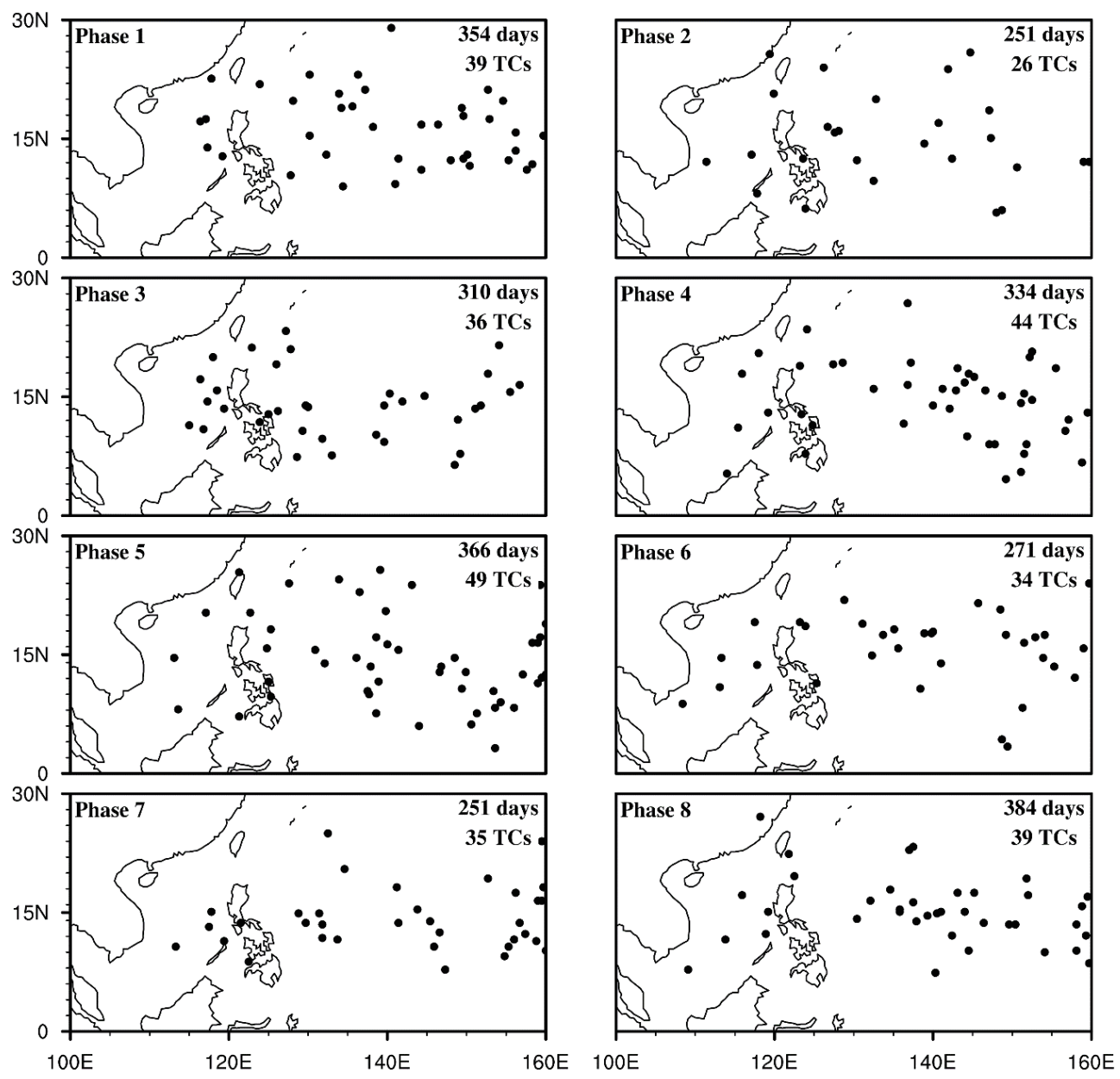

Fig. 5. The initial genesis locations of TCs in eight different phases of MJO from the HiRAM present-day simulation (1980 - 2004). The numbers on the top-right corner of each panel denote the number of days and the number of TCs for the corresponding phase.

Table 1. Daily genesis rate (DGR, in \%) of TCs in eight different phases of MJO from the HiRAM present-day simulation (1980 - 2004).

\begin{tabular}{c|ccccccccc}
\hline Phase & $\mathbf{1}$ & $\mathbf{2}$ & $\mathbf{3}$ & $\mathbf{4}$ & $\mathbf{5}$ & $\mathbf{6}$ & $\mathbf{7}$ & $\mathbf{8}$ & Mean \\
\hline DGR & 11.02 & 10.36 & 11.61 & 13.17 & 13.39 & 12.55 & 13.94 & 10.16 & 11.97 \\
\hline
\end{tabular}



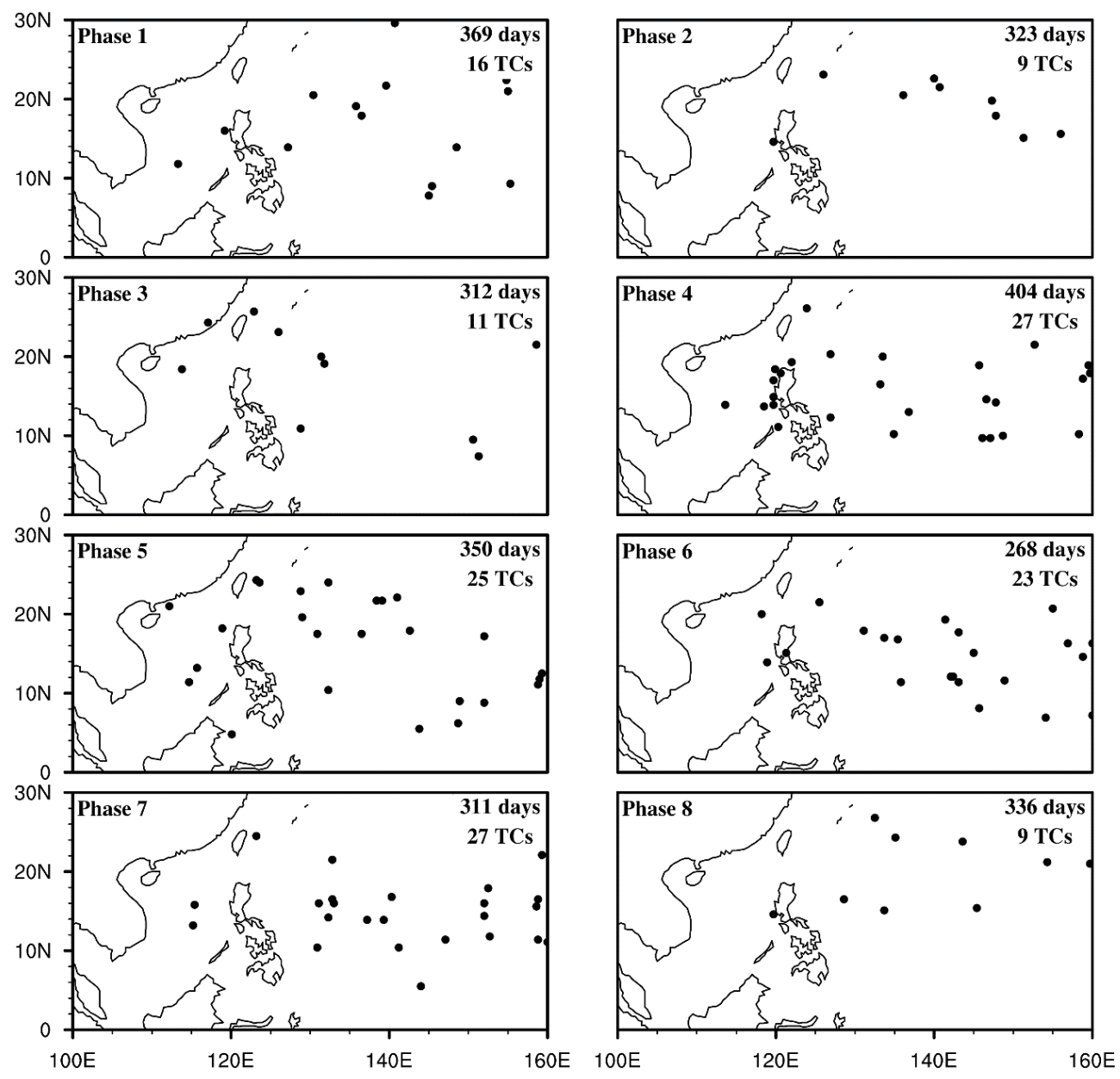

Fig. 6. Same as in Fig. 5, but for results from the HiRAM late $21^{\text {st }}$ century projection (2075 - 2099).

Table 2. Same as in Table 1, but for results from the HiRAM late $21^{\text {st }}$ century projection (2075 -2099).

\begin{tabular}{c|ccccccccc}
\hline Phase & $\mathbf{1}$ & $\mathbf{2}$ & $\mathbf{3}$ & $\mathbf{4}$ & $\mathbf{5}$ & $\mathbf{6}$ & $\mathbf{7}$ & $\mathbf{8}$ & Mean \\
\hline DGR & 4.34 & 2.79 & 3.53 & 6.68 & 7.14 & 8.58 & 8.68 & 2.68 & 5.50 \\
\hline
\end{tabular}


$23 \%$ larger than that over the suppressed convection phases (13.26 versus 10.78 ); while in the late $21^{\text {st }}$ century projection, the DGR value averaged over the enhanced convection phases is $132 \%$ larger than that over the suppressed convection phases (7.77 versus 3.34), implying a stronger MJO modulation on TC activity under global warming.

The total TC genesis number during the enhanced convection phases of MJO (phases 4, 5, and 6) accounts for approximately 42 and $51 \%$ of total TC formation number during eight MJO phases for the present-day simulation and late $21^{\text {st }}$ century projection, respectively. Because the majority of TCs form during convectively active phases of MJO, in the following analyses, we specifically focus on these three phases. Figure 7 compares the TC passage frequency during the enhanced convection phases of MJO in the WNP from the JTWC observation, present-day simulation and late $21^{\text {st }}$ century projection. In Fig. 7, the TC passage frequency is calculated as the total TC number passing over each $2.5^{\circ} \times$ $2.5^{\circ}$ grid box per year to include the effect of TC tracks. In the JTWC observation, the maximum TC frequency occurs mainly over the region $\left(10-20^{\circ} \mathrm{N}, 120-140^{\circ} \mathrm{E}\right)$. Although the modeled TC frequency is slightly weaker compared to the JTWC observation, HiRAM still captures the general pattern of TC frequency, with larger values of TC frequency over the area $\left(10-20^{\circ} \mathrm{N}, 120-140^{\circ} \mathrm{E}\right)$. The correlation coefficient between JTWC observation and HiRAM simulation is 0.72 . In the late $21^{\text {st }}$ century projection, TC frequency decreases significantly in the WNP. The greatest reduction occurs over the region where the maximum simulated TC frequency is located. In summary, under global warming, both TC genesis number and TC frequency during the enhanced convection phases of MJO are expected to decrease significantly in the WNP as projected by HiRAM under the RCP 8.5 warming scenario.

\subsection{Mechanisms for Suppressed TC genesis}

To examine the capability of the modified GPI in representing the TC genesis potential, Fig. 8 illustrates the spatial distribution of GPI during the enhanced convection phases of MJO derived from the ERA-interim data, the HiRAM present-day simulation and late $21^{\text {st }}$ century projection. The overall distribution of TC genesis in the WNP during the active MJO phases is well represented by GPI. The maximum GPI occurs to the north of $10^{\circ} \mathrm{N}$ and to the west of $140^{\circ} \mathrm{E}$, generally coinciding with the maximum TC formation region (see Figs. 7a and 8a for comparison). The spatial pattern of GPI from the ERA-interim data is reproduced by GPI from the HiRAM present-day simulation except for a weaker amplitude. Again, HiRAM projects a significant decrease in GPI during the late $21^{\text {st }}$ century period (2075 2099), which is in good agreement with the reduction of TC genesis number shown in Fig. 6.

A qualitative analysis of the GPI terms using Eq. (3) during the enhanced convection phases of MJO is conducted to explore the environmental factors causing the GPI change in the WNP. Figure 9 shows the changes in cGPI and the environmental factors between the present-day and late $21^{\text {st }}$ century projection periods. As shown, the negative anomalies of cGPI come mainly from the decrease in low-level vorticity (cRV term), followed by the reduction in mid-level relative humidity (cRH term). The decrease in potential intensity (cPI term) only make a small contribution. In contrast, the reduced vertical wind shear (cVWS term) tends to increase cGPI which is against the reduced cGPI, but its magnitude is small compared to the two leading factors. In summary, the anomalous GPI pattern shown in Fig. 9a results mainly from the decreased low-level vorticity, with an additional contribution from the reduced mid-level relative humidity.

\section{CONCLUDING REMARKS}

In this study, a pair of GFDL HiRAM experiments at approximately $25 \mathrm{~km}$ spatial resolution, one for the presentday simulation forced by lower boundary conditions from observations and the other for the late $21^{\text {st }}$ century projection forced by boundary conditions from CMIP5 multi-model means with the RCP 8.5 scenario, was conducted to examine how the impacts of MJO on TC activity over the WNP might change under global warming. From the present-day simulation, we note that HiRAM is capable of reproducing major features of the observed TC activity, including seasonal cycle and spatial distribution of TC genesis, as well as the impacts of MJO on TC activity. Under global warming, we find that the basic structure of MJO variability does not change too much except for weaker amplitudes of negative OLR anomalies (i.e., convection), especially from phases 4 to 6 , which is quite consistent with the suppressed TC formation during this period. Moreover, HiRAM projects a marked reduction of TC genesis (e.g., the DGR is cut approximately in half) in all phases of MJO and a greater DGR contrast between the enhanced (i.e., 4, 5, and 6) and suppressed (i.e., 7, 8, 1, 2, and 3) phases of MJO during the late $21^{\text {st }}$ century period $(2075-2099)$ against the present-day period (1980 - 2004).

A new GPI modified from the ENGPI, in which absolute vorticity term is replaced by relative vorticity weighted by the Coriolis parameter, is proposed to elucidate the environmental factors attributing to TC activity changes associated with MJO variability. In general, the new GPI properly reproduces the spatial distribution of TC genesis during the enhanced convection phases of MJO (i.e., phases 4,5 , and 6) and also projects a marked reduction in TC genesis number under global warming similar to observations and simulations. A budget analysis of GPI further indicates that the marked suppression of TC genesis during both the enhanced and suppressed phases of MJO under global 
(a)

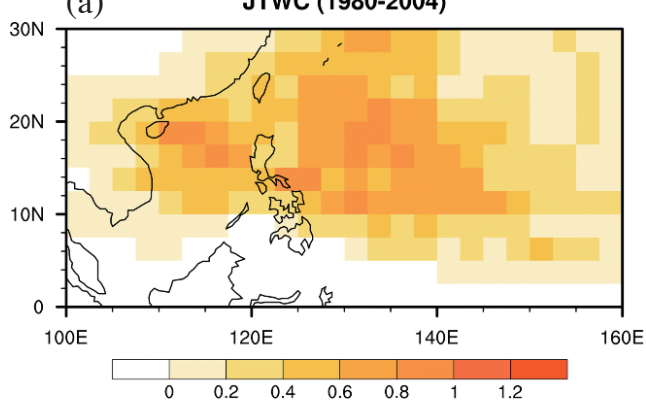

(c)

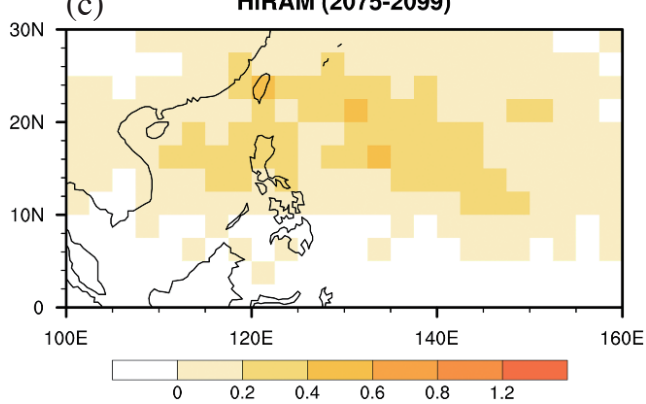

(b)

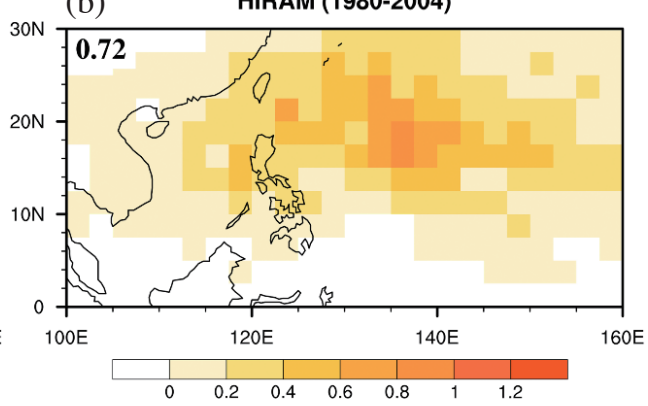

(d)

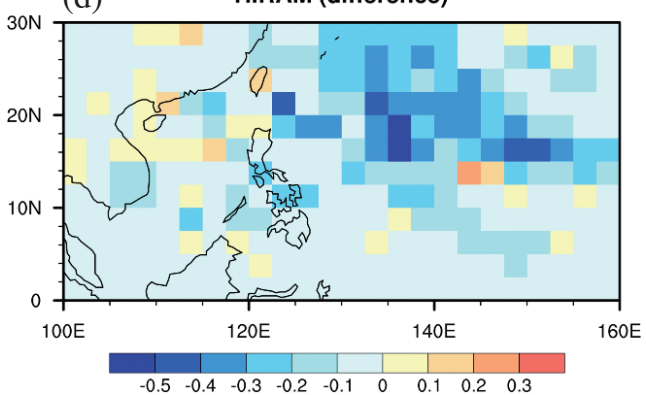

Fig. 7. The spatial distribution of TC passage frequency, calculated as the total TC number passing over each $2.5^{\circ} \times 2.5^{\circ}$ grid box per year to include the effect of TC tracks, during the enhanced convection phases of MJO from June to November for the period 1980 - 2004 for (a) JTWC, (b) HiRAM, (c) same as (b) but for the period 2075 - 2099, and (d) difference between the HiRAM present-day simulation and late $21^{\text {st }}$ century projection (latter - former). The number in the top-left corner of (b) is the pattern correlation coefficient between JTWC observation and HiRAM present-day simulation.
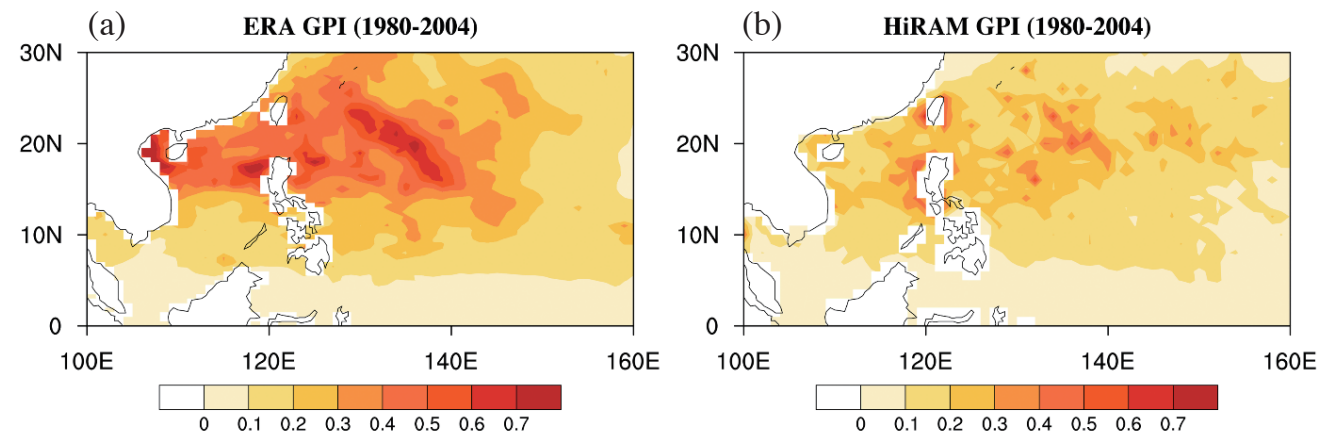

(c) HiRAM GPI (2075-2099)

(d)
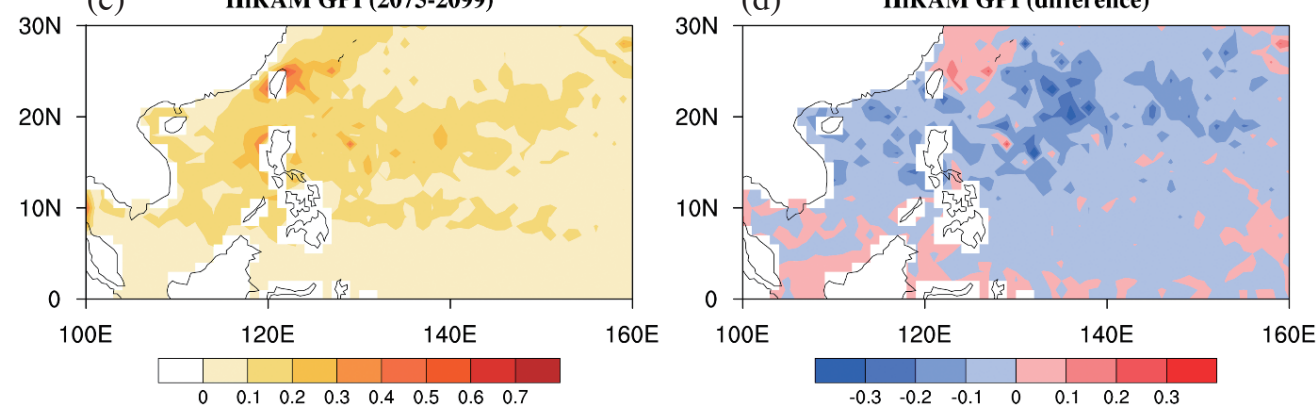

Fig. 8. The spatial distribution of GPI during the enhanced convection phases of MJO from June to November for the period $1980-2004$ derived from (a) ERA observation, (b) HiRAM present-day simulation, (c) HiRAM late $21^{\text {st }}$ century projection during the period $2075-2099$, and (d) the difference between (b) and (c) (latter - former). 
(a) Logarithm of total GPI change

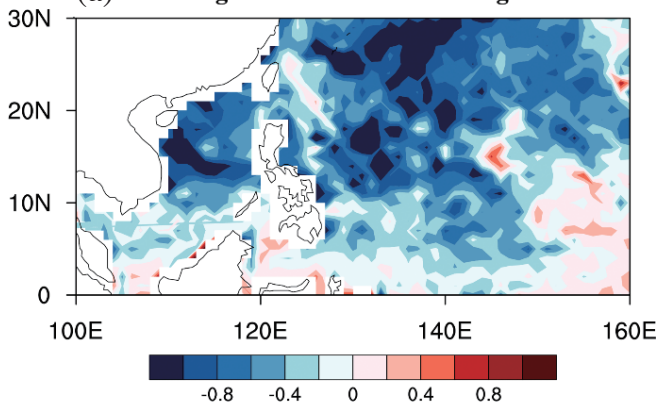

(c) Logarithm of GPI change (RV)

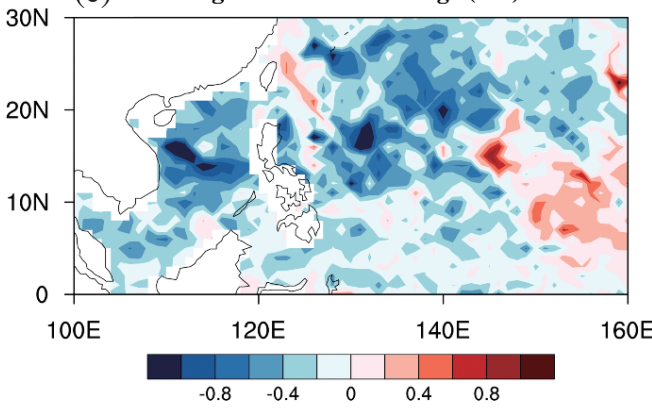

(e) Logarithm of GPI change (VWS)

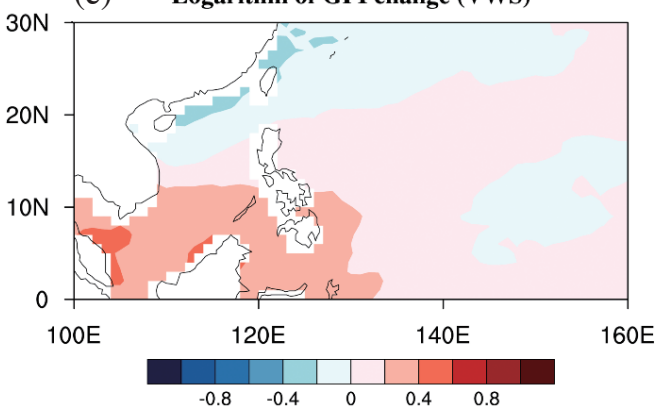

(b) Logarithm of GPI change (RH)

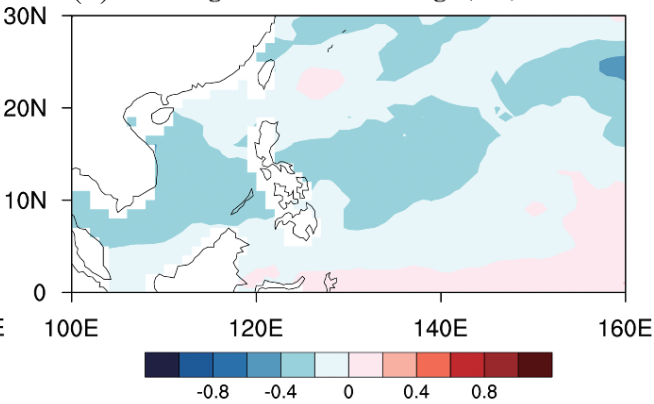

(d) Logarithm of GPI change (PI)

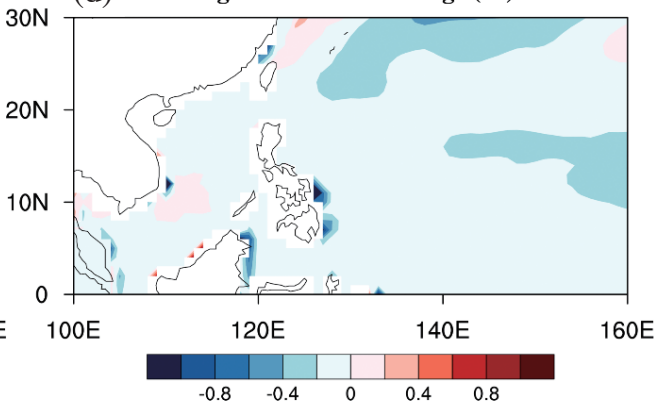

Fig. 9. The spatial distribution of (a) CGPI anomalies between HiRAM present-day simulation and late $21^{\text {st }}$ century projection, and the associated anomalies of environmental factors including (b) cRH, (c) cRV, (d) cPI, and (e) cVWS.

warming should result from decreases in low-level relative vorticity and mid-level relative humidity. On the contrary, while the reduced vertical wind shear seems to favor TC genesis; its amplitude is not strong enough to compete with the above two leading effects. The contribution from potential intensity change is very modest.

One should note that the success of TC genesis frequency simulation is dependent on the climate models' ability to adequately reproduce the large-scale atmospheric and oceanic conditions (e.g., atmospheric stability, low-level vorticity, mid-level humidity, vertical wind shear, upper ocean heat content, etc.) that are closely associated with TC genesis. Recent progresses in the state-of-the-art highresolution climate models and the convergence of simulation results obtained from different modelling groups have provided more confidence in projecting how TC genesis frequency might change with global warming. The present study highlights an example of HiRAM's application in simulating the impacts of MJO on TC activity and project- ing the potential changes in TC-MJO relation under global warming over the WNP basin.

Acknowledgements This study was sponsored by the Ministry of Science and Technology (MOST) of Taiwan under Grants MOST 108-2111-M-008-038 and MOST 1092111-M-008-010. The ERA-interim reanalysis and the TC best-track data were downloaded from the Climate Data Guide website under UCAR (University Corporation for Atmospheric Research) at https://climatedataguide.ucar. edu/climate-data and the National Center for Environmental Information website under NOAA (National Oceanic and Atmospheric Administration) at http://www.ncdc.noaa. gov/ibtracs, respectively. The HiRAM simulations were conducted and archived at the Research Center for Environmental Changes, Academia Sinica in Taipei, Taiwan. The authors thank the two anonymous reviewers for their helpful comments and suggestions to improve the quality of this study. 


\section{REFERENCES}

Arnold, N. P., M. Branson, Z. Kuang, D. A. Randall, and E. Tziperman, 2015: MJO intensification with warming in the superparameterized CESM. J. Clim., 28, 27062724, doi: 10.1175/JCLI-D-14-00494.1. [Link]

Bister, M. and K. A. Emanuel, 2002: Low frequency variability of tropical cyclone potential intensity 1 . Interannual to interdecadal variability. J. Geophys. Res., 107, D24, doi: 10.1029/2001JD000776. [Link]

Bretherton, C. S., J. R. McCaa, and H. Grenier, 2004: A new parameterization for shallow cumulus convection and its application to marine subtropical cloudtopped boundary layers. Part I: Description and 1D results. Mon. Weather Rev., 132, 864-882, doi: 10.1175/1520-0493(2004)132<0864:ANPFSC >2.0. CO;2. [Link]

Bui, H. X. and E. D. Maloney, 2018: Changes in MaddenJulian oscillation precipitation and wind variance under global warming. Geophys. Res. Lett., 45, 71487155, doi: 10.1029/2018GL078504. [Link]

Camargo, S. J., M. C. Wheeler, and A. H. Sobel, 2009: Diagnosis of the MJO modulation of tropical cyclogenesis using an empirical index. J. Atmos. Sci., 66, 30613074, doi: 10.1175/2009JAS3101.1. [Link]

Chan, J. C. L., 2005: Interannual and interdecadal variations of tropical cyclone activity over the western North Pacific. Meteorol. Atmos. Phys., 89, 143-152, doi: 10.1007/s00703-005-0126-y. [Link]

Cui, J. and T. Li, 2019: Changes of MJO propagation characteristics under global warming. Clim. Dyn., 53, 5311-5327, doi: 10.1007/s00382-019-04864-4. [Link]

Dao, L. T. and J.-Y. Yu, 2021a: Impacts of Madden-Julian Oscillation on tropical cyclone activity over the South China Sea: observations versus HiRAM simulations. Int. J. Climatol., 41, 830-845, doi: 10.1002/joc.6673. [Link]

Dao, L. T. and J.-Y. Yu, 2021b: Changes of local tropical cyclone activity over the South China Sea under global warming in high-resolution atmospheric model projections. Int. J. Climatol., doi: 10.1002/joc.7401. (in press) [Link]

Dee, D. P., S. M. Uppala, A. J. Simmons, P. Berrisford, P. Poli, S. Kobayashi, U. Andrae, M. A. Balmaseda, G. Balsamo, P. Bauer, P. Bechtold, A. C. M. Beljaars, L. van de Berg, J. Bidlot, N. Bormann, C. Delsol, R. Dragani, M. Fuentes, A. J. Geer, L. Haimberger, S. B. Healy, H. Hersbach, E. V. Hólm, L. Isaksen, P. Kållberg, M. Köhler, M. Matricardi, A. P. McNally, B. M. Monge-Sanz, J.-J. Morcrette, B.-K. Park, C. Peubey, P. de Rosnay, C. Tavolato, J.-N. Thépaut, and F. Vitart, 2011: The ERA-Interim reanalysis: Configuration and performance of the data assimilation system. Q.J. R. Meteorol. Soc., 137, 553-597, doi: 10.1002/qj.828.
[Link]

Emanuel, K. A. and D. S. Nolan, 2004: Tropical cyclone activity and the global climate system. 26th Conference on Hurricanes and Tropical Meteorology, American Meteorological Society, Miami, FL, United States, 240-241.

Hsiao, L.-P., C.-H. Tsou, and J.-Y. Yu, 2020: Investigating the abrupt change of tropical cyclone (TC) activity in the Western North Pacific by using different TC genesis indices. Int. J. Climatol., 40, 5959-5972, doi: 10.1002/joc.6558. [Link]

Hsu, P.-C., K.-C. Chen, C.-H. Tsou, H.-H. Hsu, C.-C. Hong, H.-C. Liang, C.-Y. Tu, and A. Kitoh, 2021: Future changes in the frequency and destructiveness of landfalling tropical cyclones over East Asia projected by high-resolution AGCMs. Earth's Future, 9, e2020EF001888, doi: 10.1029/2020EF001888. [Link]

Huang, P., C. Chou, and R. Huang, 2011: Seasonal modulation of tropical intraseasonal oscillations on tropical cyclone geneses in the western North Pacific. J. Clim., 24, 6339-6352, doi: 10.1175/2011JCLI4200.1. [Link]

Jiang, X., M. Zhao, and D. E. Waliser, 2012: Modulation of tropical cyclones over the eastern Pacific by the intraseasonal variability simulated in an AGCM. J. Clim., 25, 6524-6538, doi: 10.1175/JCLI-D-11-00531.1. [Link]

Kim, D., M.-I. Lee, H.-M. Kim, S. D. Schubert, and J. H. Yoo, 2014: The modulation of tropical storm activity in the Western North Pacific by the Madden-Julian Oscillation in GEOS-5 AGCM experiments. Atmos. Sci.Lett., 15, 335-341, doi: 10.1002/as12.509. [Link]

Kim, J.-H., C.-H. Ho, H.-S. Kim, C.-H. Sui, and S. K. Park, 2008: Systematic variation of summertime tropical cyclone activity in the western North Pacific in relation to the Madden-Julian oscillation. J. Clim., 21, 11711191, doi: 10.1175/2007JCLI1493.1. [Link]

Li, R. C. Y. and W. Zhou, 2013: Modulation of western North Pacific tropical cyclone activity by the ISO. Part I: Genesis and intensity. J. Clim., 26, 2904-2918, doi: 10.1175/JCLI-D-12-00210.1. [Link]

Li, Y.-X. and J.-Y. Yu, 2020: Why rare tropical cyclone formation after maturity of super El Niño events in the western North Pacific. Terr. Atmos. Ocean. Sci., 31, 21-32, doi: 10.3319/TAO.2019.06.23.01. [Link]

Lin, S.-J., 2004: A "vertically Lagrangian" finite-volume dynamical core for global models. Mon. Weather Rev., 132, 2293-2307, doi: 10.1175/15200493(2004)132<2293:AVLFDC>2.0.CO;2. [Link]

Madden, R. A. and P. R. Julian, 1971: Detection of a 40-50 day oscillation in the zonal wind in the tropical Pacific. J. Atmos. Sci., 28, 702-708, doi: 10.1175/1520-0469(1971)028<0702:DOADOI $>2.0$. $\mathrm{CO} ; 2$. [Link]

Murakami, H., B. Wang, and A. Kitoh, 2011: Future change 
of western North Pacific typhoons: Projections by a 20-km-mesh global atmospheric model. J. Clim., 24, 1154-1169, doi: 10.1175/2010JCLI3723.1. [Link]

Murakami, H., Y. Wang, H. Yoshimura, R. Mizuta, M. Sugi, E. Shindo, Y. Adachi, S. Yukimoto, M. Hosaka, S. Kusunoki, T. Ose, and A. Kitoh, 2012: Future changes in tropical cyclone activity projected by the new high-resolution MRI-AGCM. J. Clim., 25, 3237 3260, doi: 10.1175/JCLI-D-11-00415.1. [Link]

Murakami, H., P.-C. Hsu, O. Arakawa, and T. Li, 2014: Influence of model biases on projected future changes in tropical cyclone frequency of occurrence. J. Clim., 27, 2159-2181, doi: 10.1175/JCLI-D-13-00436.1. [Link]

Rayner, N. A., D. E. Parker, E. B. Horton, C. K. Folland, L. V. Alexander, D. P. Rowell, E. C. Kent, and A. Kaplan, 2003: Global analyses of sea surface temperature, sea ice, and night marine air temperature since the late nineteenth century. J. Geophys. Res., 108, 4407, doi: 10.1029/2002JD002670. [Link]

Subramanian, A., M. Jochum, A. J. Miller, R. Neale, H. Seo, D. Waliser, and R. Murtugudde, 2014: The MJO and global warming: A study in CCSM4. Clim. Dyn., 42, 2019-2031, doi: 10.1007/s00382-013-1846-1. [Link]

Tsou, C.-H., P.-Y. Huang, C.-Y. Tu, C.-T. Chen, T.-P. Tzeng, and C.-T. Cheng, 2016: Present simulation and future Typhoon activity projection over western North Pacific and Taiwan/East Coast of China in 20-km HiRAM climate model. Terr. Atmos. Ocean. Sci., 27, 687-703, doi: 10.3319/TAO.2016.06.13.04. [Link]

Wang, B. and J.-Y. Moon, 2017: An anomalous genesis potential index for MJO modulation of tropical cyclones. J. Clim., 30, 4021-4035, doi: 10.1175/JCLID-16-0749.1. [Link]

Wheeler, M. C. and H. H. Hendon, 2004: An all-season real-time multivariate MJO index: Development of an index for monitoring and prediction. Mon. Weather Rev., 132, 1917-1932, doi: 10.1175/1520-0493(2004)132<1917:AARMMI>2.0. CO;2. [Link]

Ying, M., T. R. Knutson, H. Kamahori, and T.-C. Lee, 2012: Impacts of climate change on tropical cyclones in the Western North Pacific Basin. Part II: Late twenty-first century projections. Trop. Cyclone Res. Rev., 1, 231241, doi: 10.6057/2012TCRR02.09. [Link]

Yoshida, R., Y. Kajikawa, and H. Ishikawa, 2014: Impact of boreal summer intraseasonal oscillation on environment of tropical cyclone genesis over the western North Pacific. SOLA, 10, 15-18, doi: 10.2151/sola.2014-004. [Link]

Yu, J.-Y., L.-P. Hsiao, and P.-G. Chiu, 2018: Evaluating the Emanuel-Nolan genesis potential index: Contrast between North Atlantic and western North Pacific. Terr. Atmos. Ocean. Sci., 29, 201-214, doi: 10.3319/ TAO.2017.09.27.01. [Link]
Yumoto, M. and T. Matsuura, 2001: Interdecadal variability of tropical cyclone activity in the western North Pacific. J. Meteorol. Soc. Jpn., 79, 23-35, doi: 10.2151/ jmsj.79.23. [Link]

Zhao, C. and T. Li, 2019: Basin dependence of the MJO modulating tropical cyclone genesis. Clim. Dyn., 52, 6081-6096, doi: 10.1007/s00382-018-4502-y. [Link]

Zhao, C., H.-L. Ren, R. Eade, Y. Wu, J. Wu, and C. MacLachlan, 2019: MJO modulation and its ability to predict boreal summer tropical cyclone genesis over the northwest Pacific in Met Office Hadley Centre and Beijing Climate Center seasonal prediction systems. Q.J.R. Meteorol.Soc., 145, 1089-1101, doi: 10.1002/ qj.3478. [Link]

Zhao, H., X. Jiang, and L. Wu, 2015: Modulation of northwest Pacific tropical cyclone genesis by the intraseasonal variability. J. Meteorol. Soc. Jpn., 93, 81-97, doi: 10.2151/jmsj.2015-006. [Link]

Zhao, M., I. M. Held, S.-J. Lin, and G. A. Vecchi, 2009: Simulations of global hurricane climatology, interannual variability, and response to global warming using a 50-km resolution GCM. J. Clim., 22, 6653-6678, doi: 10.1175/2009JCLI3049.1. [Link]

\section{APPENDIX A. GPI ANALYSIS DURING THE SUPPRESSED CONVECTION PHASES}

Although the majority of TCs forms during the convectively active $\mathrm{MJO}$ phases, the factors responsible for changes of TC genesis during the convectively inactive MJO phases are also worth to discuss. Figure A1 compares the spatial distribution patterns of TC genesis frequency and GPI during the suppressed convection phases of MJO (phases 1,2,3,7, and 8) over the WNP between the presentday simulation (1980 - 2004) and late $21^{\text {st }}$ century projection (2075 - 2099). The TC genesis frequency is calculated as the total TC number forming over each $2.5^{\circ} \times 2.5^{\circ}$ grid box per year. In the present-day simulation, larger values of TC genesis frequency occur over the region $\left(10-20^{\circ} \mathrm{N}, 115-\right.$ $160^{\circ} \mathrm{E}$ ) (Fig. A1a). The TC genesis frequency is projected to decrease significantly in the late $21^{\text {st }}$ century under global warming (Fig. A1c). The greatest reduction occurs over the most active TC formation region $\left(10-20^{\circ} \mathrm{N}, 115-160^{\circ} \mathrm{E}\right)$ (Fig. A1e). In general, the GPI reproduces the spatial distribution of TC genesis frequency during the suppressed MJO phases, with greater values of GPI over the active TC formation area (Fig. A1b). Moreover, the GPI also properly reproduces the significant decrease of TC genesis over the area $\left(10-20^{\circ} \mathrm{N}, 120-160^{\circ} \mathrm{E}\right)$ (Figs. A1d and f), which is generally consistent with the area of reduced TC formation (Fig. A1e).

A budget analysis of GPI during the suppressed convection phases of MJJO is also conducted to explore the environmental factors attributing to the TC genesis changes. 
Figure A2 shows the changes in cGPI and the environmental factors between the present-day simulation and late $21^{\text {st }}$ century projection during the inactive MJO phases. The negative anomalies of cGPI over the region $\left(10-20^{\circ} \mathrm{N}, 120\right.$ $-160^{\circ} \mathrm{E}$ ) appear to come from the decreased low-level vorticity (cRV term), followed by the reduced mid-level relative humidity (cRH term). Although the increase in potential intensity (cPI term) and the decrease in vertical wind shear (cVWS term) tend to increase cGPI, their maxima are not located in the active formation area. Therefore, their contribution to the change of TC formation should be small. In summary, the decrease in TC genesis frequency during the suppressed convection phases also comes from decreases in low-level vorticity and mid-level relative humidity similar to the enhanced convection phases. We also note that the contribution of potential intensity to the anomalous GPI pattern is different between the enhanced and suppressed convection phases. For example, the change in potential intensity tends to decrease cGPI during the enhanced convection phases, but the change tends to increase cGPI during the suppressed convection phases (see Figs. 9d and A2d for comparison).

\section{APPENDIX B. TC GENESIS FREQUENCY DURING THE ENHANCED CONVECTION PHASES}

Figure B1 compares the TC genesis frequency, calculated as the total $\mathrm{TC}$ genesis number at each $2.5^{\circ} \times 2.5^{\circ}$ grid box per year, during the enhanced convection phases of MJO over the WNP from the JTWC observation, the present-day simulation and the late $21^{\text {st }}$ century projection. As shown in the JTWC observation (Fig. B1a), most TCs form over the major genesis region $\left(5-20^{\circ} \mathrm{N}, 100-160^{\circ} \mathrm{E}\right)$. Although there exist certain discrepancies, the general pattern of TC genesis frequency is captured by HiRAM with greater values of TC genesis frequency occurring over the major genesis region (Fig. B1b). The model slightly underestimates the TC formation frequency in the WNP, which is consistent with the underestimate of GPI during the enhanced convection phases of MJO (see Fig. 8). In the late
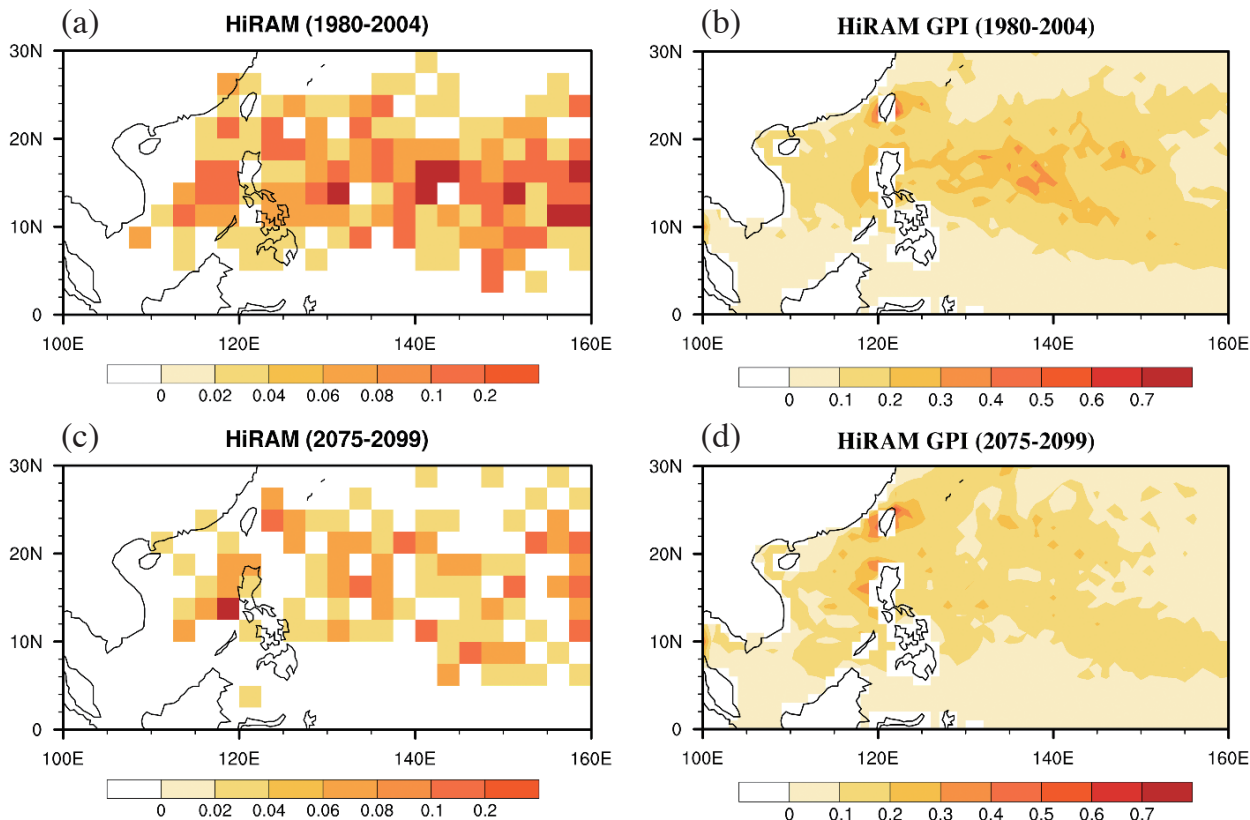

(d)
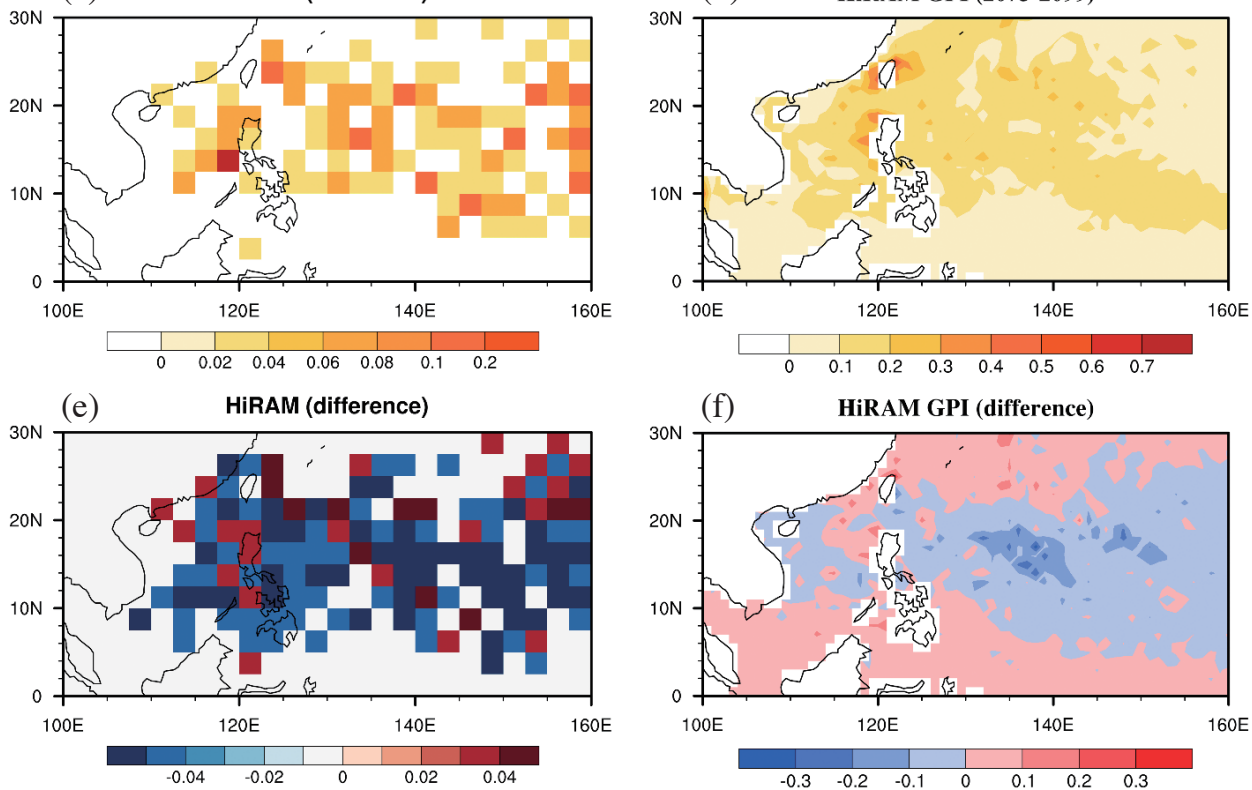

Fig. A1. The distribution of TC genesis frequency, calculated as the total TC genesis number at each $2.5^{\circ} \times 2.5^{\circ}$ grid box per year, and GPI during the suppressed convection phases of MJO from June to November from (a) (b) HiRAM simulation during the period 1980 - 2004, (c) (d) HiRAM projection during the period 2075 - 2099 and (e) (f) difference between the HiRAM simulation and projection (latter - former). 
(a) Logarithm of total GPI change

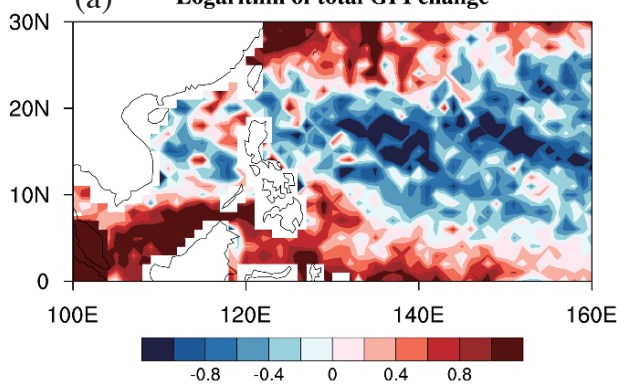

(c) Logarithm of GPI change (RH)

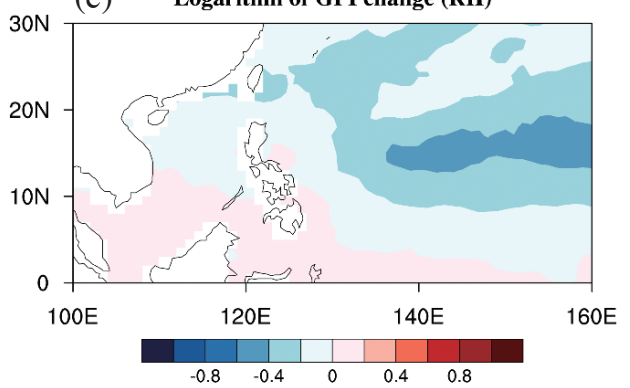

(e) Logarithm of GPI change (VWS)

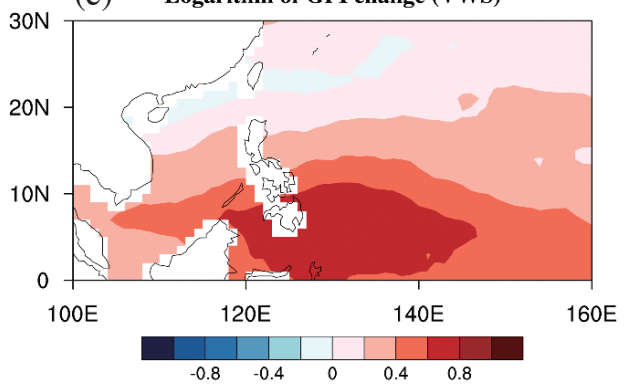

(b) Logarithm of GPI change (RV)

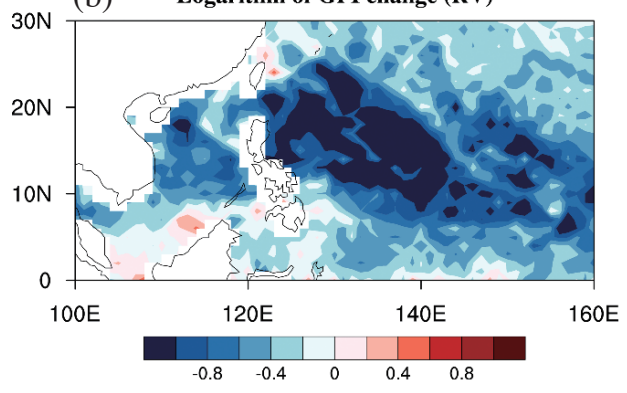

(d) Logarithm of GPI change (PI)

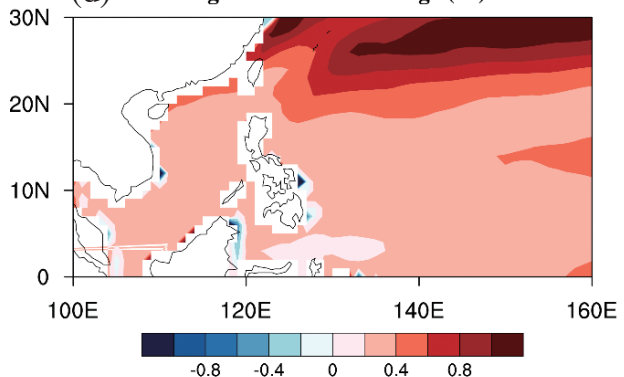

Fig. A2. Same as Fig. 9 in the paper, but for the suppressed convection phases of MJO.
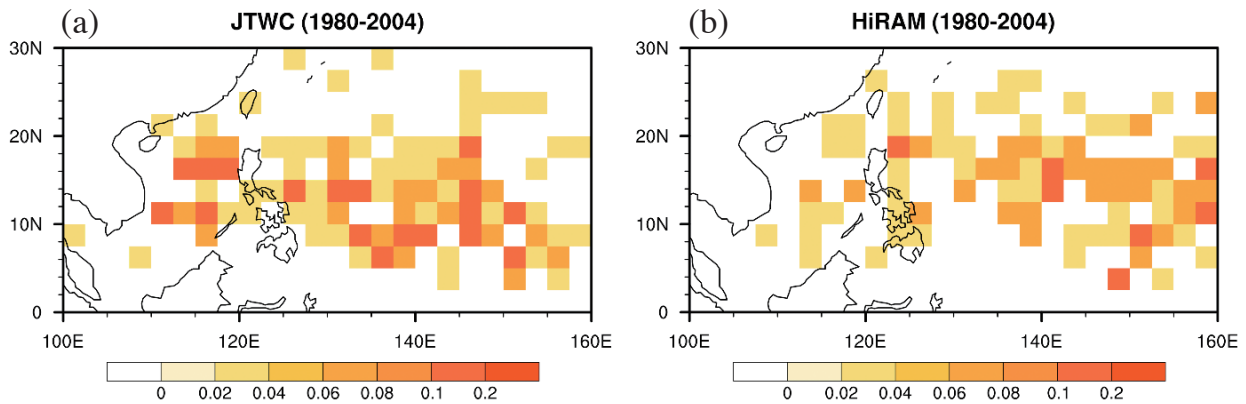

(c)

HiRAM (2075-2099)

(d)
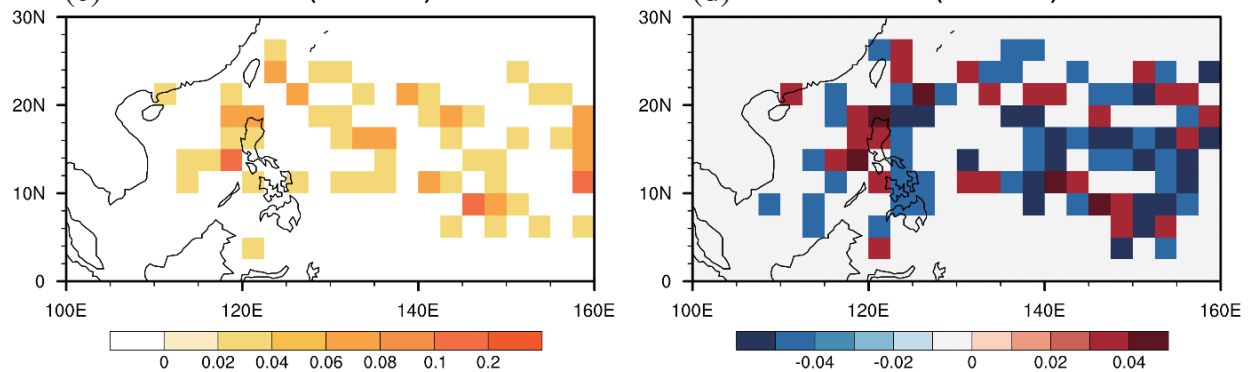

Fig. B1. The spatial distribution of TC genesis frequency, calculated as the total TC genesis number at each $2.5^{\circ} \times 2.5^{\circ}$ grid box per year, during the enhanced convection phases of MJO from June to November over the present-day period for (a) JTWC and (b) HiRAM, (c) same as (b) but for the HiRAM late $21^{\text {st }}$ century projection, and (d) difference between (b) and (c) (latter - former). 
$21^{\text {st }}$ century period, the TC genesis frequency during the enhanced convection phases is projected to decrease significantly, confirming the reduction in TC formation associated with MJO variability under global warming. The greatest decrease again occurs over the major genesis region (5 $20^{\circ} \mathrm{N}, 100-160^{\circ} \mathrm{E}$ ).

We also note that while HiRAM slightly overestimates the TC genesis frequency for all TC events (Fig. 2), when focusing on the enhanced convection phases of MJO (i.e., the MJO-TC interaction), the simulated TC genesis frequency appears to be weaker compared to the JTWC observation (see Figs. B1a and b for comparison). This implies a weaker TC genesis contrast between the enhanced and suppressed MJO phases in HiRAM simulations compared to the observations which is a common feature in most general circulation models as pointed out by Dao and Yu (2021a). 